\title{
ANTECEDENTES PARA LA HISTORIA SOCIAL DE MAGALLANES. NEGROS Y MULATOS EN EL ANTIGUO TERRITORIO DE COLONIZACIÓN
}

MATEO MARTINIC B. ${ }^{1}$

\section{RESUMEN}

Se entregan los primeros antecedentes conocidos acerca de la presencia de negros y mulatos en el antiguo Magallanes. Se da cuenta del origen de la misma y del grado de permanencia, así como de la incorporación de aquellos que decidieron permanecer en el territorio y de su incorporación a la sociedad en formación.

PALABRAS CLAVES: Patagonia, negros y mulatos, historia social.

\section{NEW INFORMATION OF THE SOCIAL HISTORY OF MAGELLAN. BLACK AND CROSSBRED PEOPLE IN THE OLD TERRITORY}

\begin{abstract}
The first evidences of black and crossbred people in the old Magellan Territory is given. There origin and degree of permanence or destiny and paper in this incipient society is considered.

KEY WORDS: Patagonia, black and crossbred people, social history.

Las tierras del meridión americano parecen no constituir un ambiente favorable para los africanos. De hecho, en una compulsa rápida sólo encontramos referencias de paso, las más antiguas, y de manera excepcional el registro de una presencia más prolongada en el tiempo.

La flotilla descubridora de Fernando de Magallanes traía en el conjunto étnicamente variopinto de su tripulación, cinco o seis negros africanos, todos esclavos, en calidad de sirvientes de algunos de los oficiales superiores. En efecto, de uno de ellos se ha conservado el nombre, Antón,

"de color negro" para más señas, que pertenecía a Gonzalo Gómez de Espinoza, maestre de armas o alguacil mayor que anduvo embarcado en la nave capitana Trinidad.

Se sabe, asimismo, que en la carabela San Luis, con la que el capitán Juan Ladrillero realizara en 1557-58 su memorable periplo exploratorio por los canales occidentales de la Patagonia y por el estrecho de Magallanes, había un negro entre los tripulantes, quien estuvo entre la media docena de hombres que sobrevivieron a la brava expedición de aquel capitán.

1 Centro de Estudios del Hombre Austral, Instituto de la Patagonia, Universidad de Magallanes. Casilla de Correo 113-D, Punta Arenas, Magallanes, Chile.
\end{abstract}


Si hubo o no africanos entre la gente (tripulantes, soldados y pobladores) que en 1581 embarcó en Cádiz en la flota que partió con rumbo al estrecho de Magallanes para fortificar sus costas para dificultar el tráfico de navíos extraños por el mismo, y de establecer poblaciones en el litoral, de acuerdo con el proyecto propuesto por el capitán Pedro Sarmiento de Gamboa al rey Felipe II de España y aprobado por él, no es algo que pueda conocerse a ciencia cierta. Pero sí se sabe que ese capitán sugirió al monarca que en el curso del viaje se recalara en Cabo Verde o en Brasil para recoger allí algunos esclavos negros, para que pudieran desempeñarse en el Estrecho en faenas pesadas. Pero no hay constancia fehaciente sobre si alguno pudo ser efectivamente embarcado.

Dando por supuesto que en las diferentes navegaciones que se hicieron con posterioridad al arribo de Sarmiento (1584) y hasta comienzos del siglo XIX, que más de algún africano viajara a bordo de diferentes naves y por tanto pasara por las aguas de Magallanes, de manera comprobada la presencia de negros en el meridión ha estado asociada al paso de naves de bandera norteamericana, tráfico que habiéndose iniciado en los comienzos del siglo XIX se hizo más nutrido y frecuente a contar de la tercera década de la centuria. Se sabe así de antiguos esclavos, ahora hombres libres, embarcados como marineros de cubierta o cocineros. Entre ellos estuvo Isaac Williams, lejos el más famoso de los que vivieron en Magallanes.

El mismo, al parecer, habría desertado hacia 1840 de una nave norteamericana durante su paso por el estrecho de Magallanes, quedándose a vivir entre los naturales del mismo, entre aquellos que moraban sobre su costa septentrional con más precisión. Quizá el sitio de su desembarco y deserción fuera puerto Peckett, paraje de recalada ocasional para las naves veleras pues allí se tenía la probabilidad de encontrar indígenas con los cuales se podía practicar algún comercio y adquirir carne de guanaco para las necesidades alimentarias, del mismo modo que abastecerse de agua. Acogido por los indígenas, es posible que éstos fueran los mismos después conocidos como guaicures o guaicurúes, supuestos mestizos de aónikenk, cazadores-recolectores de tierra adentro, y kawéskar, nómades marinos que solían frecuentar las costas del istmo de la península de Brunswick. Entre ellos tomó una mujer, con la que tuvo dos hijos. Nos mueve a suponer tal vinculación pues no sólo se le vio más tarde con los guaicurúes, sino también por la información recogida por Robert Fitz Roy entre los aónikenk de San Gregorio, en cuanto que los mismos sienten gran antipatía por los negros. En cuanto ven a uno le arman gritería y silbatina y le hacen muecas ${ }^{1}$.

Tras unos cuatro años de convivencia entre los indígenas, hastiado quizá de su miseria, Williams añorando tal vez la mejor vida marinera de antaño, aprovechó el paso de una nave ballenera por el estrecho de Magallanes y se embarcó en la misma con rumbo a San Carlos de Ancud. Una vez allí se contrató como marinero en el queche nacional Magallanes, que zarpó para el Estrecho a comienzos de 1844, viaje durante el que, al parecer, conoció a fray Domingo Pasolini que iba a Fuerte Bulnes para hacerse cargo del servicio religioso de la colonia, que supo de sus aventuras, pues es él quien dio cuenta posteriormente de tal circunstancia. El franciscano vio en el negro un posible colaborador para su tarea misional, vista su antigua relación con los indígenas, y así pudo conseguir que aquél fuera relevado de su servicio, a fin de ponerlo en tierra para que se venga con su familia a vivir con nosotros en el fuerte y ver modo de conseguir traiga en su compañía a uno de los caciques...2.

Antes de proseguir con las andanzas de Isaac Williams, cabe dar cuenta de que erigido el Fuerte Bulnes como expresión de guardia de soberanía para afirmar la posesión formal que la República de Chile había establecido sobre el territorio meridional del continente el 21 de setiembre de 1843, en la punta de Santa Ana, litoral de la península de Brunswick, algunas semanas después de ocurrido el hecho arribaron al lugar unos cuantos indígenas de la Patagonia en plan de conocimiento acerca de las intenciones de los recién llegados. Así entonces, la autoridad colonial, sargento mayor Pedro Silva, que había viajado en el Magallanes conjuntamente con el padre Pasolini y el secretario Santiago Dunne, valorizó igualmente la presencia del negro norteame-

$1 \quad$ Narración del viaje de los buques de S. M. 'Adventure' y 'Beagle' en los años de 1826 a 1836 (Biblioteca del Oficial de Marina, Buenos Aires 1933), tomo III, pág. 199.

2 Carta del P. Pasolini al P. Paulino Romani, de fecha 19 de febrero de 1844 (En Tres Misioneros, Publicaciones del Archivo Franciscano, Santiago 2003), pág. 73. 
ricano entre los naturales, pues al dominar su lengua el mismo podía servir como intérprete o lenguaraz y facilitar de esa manera el mejor entendimiento y relación entre los chilenos y los aborígenes de la sección nororiental del territorio. De esa manera decidió contratarlo para el servicio de la colonia.

...al mismo tiempo le he asignado $\$ 6$ de sueldo también a un negro norteamericano que hacen como cuatro años ha que anda entre los indios $y$ casado con una india natural y tiene familia $y$ este lo tengo de intérprete para que le hable a los indios y sabe hablar perfectísimamente en inglés con lo que podía entenderse a gusto con Dunne que dominaba esa lengua que le era propia y traduce lo de indio a castellano, como igualmente también lo voy a confiar en el cuidado de la Chalupa para que le ayude al marinero Santa Ana y este sueldo principió a correr desde el $1^{\circ}$ de Marzo... ${ }^{3}$.

Meses después, el sucesor de Silva en el gobierno colonial, Justo de la Rivera, en oficio dirigido al Intendente de Chiloé le hacía presente que Williams es trabajador oficioso en varios ramos y hoy mismo se ocupa de hacer una carreta para el servicio de la Colonia... ${ }^{4}$.

Pero esa buena opinión del mandatario sobre el negro norteamericano no debió durar mucho tiempo porque a comienzos de 1845, aquél estimó que Williams habría tratado de indisponer a los indios del norte con la autoridad, por lo que lo dio de baja del servicio y además lo hizo detener y poner bajo vigilancia, aunque sin tener pruebas suficientes acerca de la presunta deslealtad del mismo. En febrero de 1845 lo remitió preso a disposición del Intendente de Chiloé ${ }^{\text {. }}$

Una vez allí, de algún modo Isaac Williams se las arregló para vindicarse ante la autoridad de San Carlos de Ancud y luego, consiguió embarcarse como marinero, otra vez en el mismo queche Magallanes de antaño. Con esta nave volvió una vez más a Fuerte Bulnes y, una vez aquí, desertó del buque y se fue con sus antiguos amigos indios. En enero de 1848 retornó nuevamente a la colonia chilena, formando parte de un grupo de guaicurúes, oportunidad en que el gobernador, ahora José de los Santos Mardones,

3 Nota №11 de 18 de marzo de 1844, en diario de Guerra de Fuerte Bulnes 1844-1850 (Ediciones de la Universidad de Magallanes, Punta Arenas 1997), pág. 13.

4 Oficio de 15 de julio de 1844. Id. pág. 41.

5 Oficio de 5 de febrero de 1845. Id. pág. 61. lo hizo apresar por su condición de desertor para después ponerlo a disposición del comandante de la nave chilena, lo que ocurrió efectivamente durante febrero. A partir de ese entonces se pierde la pista de Isaac Williams, pues cesan las menciones sobre él en la correspondencia oficial, ignorándose qué pudo ser del mismo como también de los hijos que aquí se quedaron.

Sin excluir la posibilidad de alguna otra presencia negra de carácter ocasional en la colonia de Magallanes, con certidumbre se sabe que ésta sí tuvo ocurrencia, otra vez en grado de permanencia prolongada en Punta Arenas, a contar de los primeros años de la década de 1870. Para entonces el establecimiento chileno había superado algunos avatares lamentables y al cabo de un prolongado lapso de letargo y estancamiento había comenzado a cobrar nueva vida, bajo la preocupada conducción del gobernador Oscar Viel.

En efecto, entre noviembre de 1867 y setiembre de 1868 se habían puesto en vigencia varias medidas administrativas por parte del gobierno del Presidente José Joaquín Pérez en procura de la recuperación y fomento de la colonia nacional en la Patagonia. Así, se dispusieron facilidades para radicar inmigrantes laboriosos, la declaración de la libertad aduanera y la habilitación de Punta Arenas como puerto menor para el comercio marítimo. Esas y otras circunstancias de ajeno origen igualmente favorables habían contribuido y contribuían a brindar un contexto que favorecía el desarrollo de Punta Arenas, de manera ciertamente auspiciosa.

Entre los primeros que supieron aprovechar esas ventajas había estado un inmigrante portugués, José Nogueira, que se había radicado hacia 1866 y que pronto advirtió las perspectivas que ofrecía la caza de animales de piel fina, de los lobos marinos de dos pelos, que abundaban en los archipiélagos occidentales del territorio magallánico.

Fue así como el joven lusitano comenzó a desarrollar hacia 1870 una actividad independiente como empresario cinegético, armando para el caso la goleta Anita que sería la fundadora de su posterior importante flota velera. La explotación lobera era un negocio sacrificado y rudo que se realizaba en condiciones ambientales en extremo inhóspitas, sobre los parajes más expuestos a las contingencias climáticas oceánicas de los archipiélagos patagónico y fueguino, pero de un gran rendimiento económico 
habida cuenta de la buena cotización que tenían las pieles de lobos de dos pelos en los mercados peleteros de Europa. Esta explotación, importa señalarlo, sostenida por dos décadas a lo menos, devino por sus resultados económicos el fundamento de la gran fortuna que consiguió acumular José Nogueira y con la que pudo llevar adelante otros importantes emprendimientos mercantiles y fundiarios de notable envergadura, que cimentarían su fama histórica como protopionero del progreso territorial magallánico.

Necesitado como pudo estar el empresario de marineros fogueados para una faena ruda y laboriosa por demás, y no habiéndolos siempre disponibles en el puerto del Estrecho, es seguro que debió recordar a más de algún antiguo camarada y, por tanto, escribió ofreciendo trabajo. Así se explica la cantidad de lusos que estuvieron a su servicio entre 1870 y 1893 , fecha de la muerte del empresario pionero, como se comprueba con los contratos de embarque que se conservan en el archivo de su nombre, en Punta Arenas. Ello, por otra parte, fue el origen directo de la pequeña colectividad portuguesa radicada en Magallanes y que para el censo municipal de población del año 1906 alcanzó a 44 individuos.

Aunque al tiempo de publicar los resultados de nuestra primera investigación en los documentos de ese archivo (Martinic 1971), no pudimos suponer que entre tantos hubiera más de algún marinero de tal procedencia y raza negra, la evidencia sólo pudimos tenerla de manera absolutamente casual muchos años después, cuando llegó a nuestras manos en calidad de donación un cuadro con una galería de retratos, en parte incompleta por sustracción o pérdida, referida a los fundadores de la Sociedad de Beneficencia Portuguesa de Punta Arenas (1893). Las fotografías corresponden a los veintiún socios fundadores, de ellos dieciséis portugueses de origen y cinco de otras nacionalidades (Fig. 1). Los retratos fueron realizados por Manuel Alves Brazil, presidente de la entidad y que había adoptado la profesión de fotógrafo. Recorriendo las caras, salta de inmediato a la vista la presencia de siete negros entre los lusos: Benito Cardozo, Francisco Gómez, Camilo Fontes, Gonzalo Correa, Serafín Araujo, José Dos Santos y Silvestre Ramos ${ }^{6}$.

6 Archivo Fotográfico Histórico del Centro de Estudios del Hombre Austral, Instituto de la Patagonia, Universidad de Magallanes, Punta Arenas.
Esta evidencia nos llevó a entender cabalmente las contribuciones caritativas que José Nogueira hiciera en una época a la "Santa Casa de Misericordia dos officiaes e marinheiros" de Loanda, Angola, hecho que en un principio nos parecía extraño, esto es, porque la beneficiaria era una institución de la capital angoleña y no una de Lisboa o de Porto, como parecía más propio. Es que, claro está, debe tenerse por seguro que al haber negros o mulatos entre los marineros portugueses de ese empresario, éstos debieron proceder o ser originarios de alguna colonia africana del imperio portugués.

Es probable que los identificados no hayan sido los únicos negros o mulatos que inmigraron a la antigua colonia, después Territorio de Colonización de Magallanes, radicándose varios de ellos de manera permanente, pero no siempre hay forma de conocer su lugar de nacimiento y presumir, por esa vía, su raza. Una revisión realizada en los registros de matrimonios, nacimientos y defunciones de la Oficina del Servicio de Registro Civil e Identificación de Punta Arenas y correspondientes al período 18851900 , como también a los años que siguieron hasta 1920, nos permitió encontrar varias referencias que dan como lugar de origen las islas del Cabo Verde, frente a la costa de Guinea, dato también recogido por la tradición entre familias de origen luso.

Ciertamente es difícil poder determinar cuántos de esos inmigrantes portugueses pudieron ser negros o mulatos. En el Apéndice se entrega un listado de 54 individuos inmigrados entre 1871 y 1890, preparado a base de los roles de tripulaciones que obran en el Archivo Nogueira (28 nombres) y de otros documentos, principalmente de asientos en el registro de la Parroquia del Sagrado Corazón de Jesús de Punta Arenas para idéntico lapso (26 personas), del que dimos cuenta en trabajo anterior (Martinic 1975). Ahora bien, de manera fehaciente, por fotografías y referencias únicamente nos consta que dos de los incluidos en ese reducido universo de 54 personas eran efectivamente de raza blanca, y cuatro, también de modo fidedigno (por la evidencia fotográfica comentada), eran de raza negra. Queda así una indeterminada cantidad de individuos identificados solamente con sus nombres y nacionalidad entre los que más de alguno pudo tener los rasgos correspondientes a un origen racial negro.

Cuantos quieran hayan sido los sujetos de que se trata, para la historia social de Magallanes 


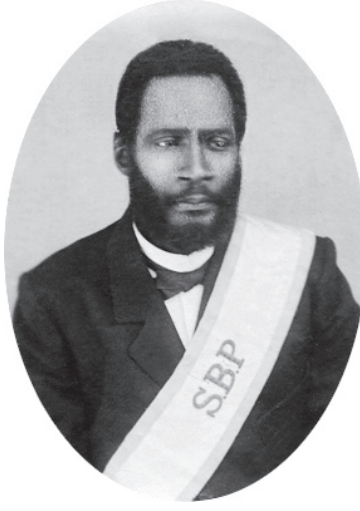

Benito Cardozo

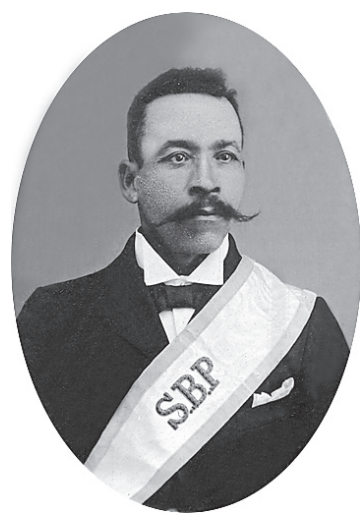

Camilo Fontes

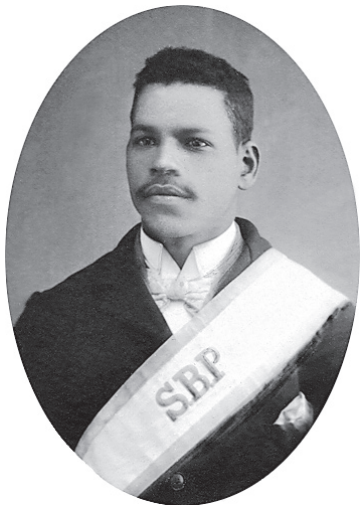

Francisco Gómez

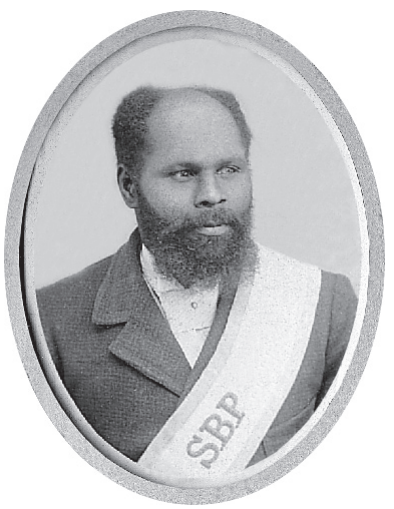

Gonzalo Correa

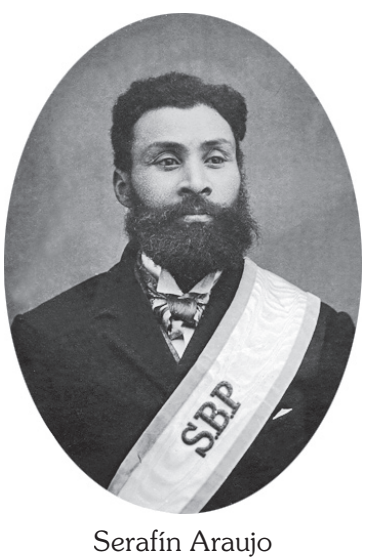

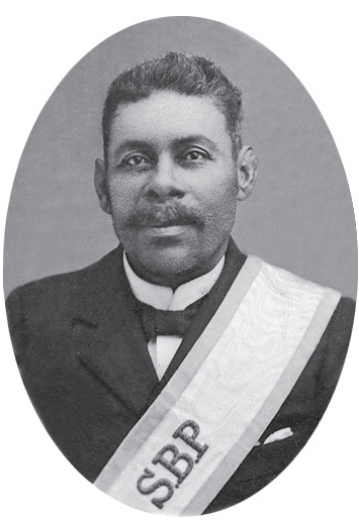

José Dos Santos

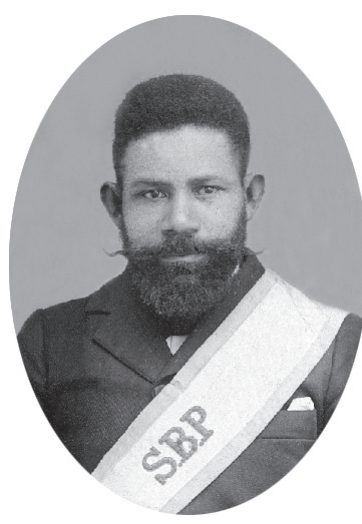

Silvestre Ramos

Fig. 1: Afro-lusitanos integrantes de la nómina de socios fundadores de la Sociedad de Beneficencia Portuguesa de Punta Arenas (1893). 
lo que interesa es que una cantidad no precisada de ellos se incorporó efectivamente a la comunidad regional en plena formación. Consta así que a lo menos uno de los tres identificados como negro, Gonzalo Correa, contrajo matrimonio con Doralisa Gutiérrez, chilena naturalmente. Consta igualmente que otros dieciocho de los inmigrantes portugueses también se unieron legal y religiosamente con mujeres de diferente origen nacional, aunque predominantemente con chilenas y, sólo en un caso, con otra paisana ${ }^{7}$. Margen pues hubo para que no una sino varias familias con miembros de sangre negra se incorporaran al crisol étnico magallánico fundacional. De hecho, recordamos haber conocido durante nuestra niñez y juventud a algunas personas de probada raigambre local que mostraban rasgos de mestizaje negroide más o menos acusados, $y$ que llevaban apellidos que hoy sabemos eran de conocido ancestro portugués.

Para concluir cabe la mención a otro hombre de raza negra que vivió en Magallanes, cobrando alguna fama. Este fue Henry o Enrique Barrington, quien llegó a Punta Arenas en 1898, cuando tenía 21 años. De elevada estatura y con una complexión física de atleta, parece haberse dedicado desde la temprana juventud a la práctica del box. Así, una vez aquí, fue quien dio a conocer y popularizó la práctica de tan rudo deporte en el medio local, midiéndose con otros pugilistas aficionados, casi todos extranjeros como él. De hecho, la primera pelea de exhibición de que hay recuerdo tuvo lugar en el teatro Cosmopolita el 4 de agosto de 1898, entre Barrington y el escocés Robert Ferries, y que concluyó en empate. Siguieron después otros encuentros en los que el negro enfrentó a otros británicos como John Morgan, James Mitchell, Tommy Burns y George Booth, a quienes venció cimentando una fama de campeón que le acompañaría por años.

Sacó provecho de su habilidad como una forma de ganarse la vida y así fue como en 1905 abrió la primera sala de boxeo regular en Chile, con el apoyo de algunos vecinos entusiastas que le pagaban una remuneración para que pudiera mantenerse. Por años se ocupó de la difusión del

7 Entre otros hemos compulsado el matrimonio de Eduardo Rendoll Tavares, natural de San Vicente en las islas del Cabo Verde, quien en 1917 contrajo matrimonio con Virginia Gómez Loza, chilena. deporte del box, lo que incluyó lecciones entre los alumnos del Liceo de Hombres de Punta Arenas ${ }^{8}$. Barrington se mantuvo en actividad como pugilista hasta 1921, cuando fue derrotado por otro aficionado tan fuerte como él, pero mucho más joven. Retirado definitivamente, poco a poco fue olvidado por los que otrora lo apoyaran y murió pobre y abandonado en el Hospital de Asistencia Social, en 1940, sin haber dejado descendencia conocida.

La escasa significación numérica de la incorporación social de que se trata habría sido -es una conjetura- la razón por la que la tradición vecinal no recogería de forma alguna de rechazo o discriminación por la diferencia de color en la piel, como ha ocurrido en tantas otras comunidades a lo largo y ancho del gran continente americano. Por tanto, los negros y mulatos que se integraron a la sociedad magallánica lo hicieron en plenitud y su huella étnica ya difícilmente visible, se ha subsumido hace tiempo en el conjunto humano del meridión.

\section{FUENTES DE CONSULTA}

Inédita

Archivo José Nogueira, carpetas XXIII Actividades marítimas. Caza de lobos. Cabotaje y XXIX Documentos varios. Museo Regional de Magallanes, Punta Arenas.

Archivo Servicio del Registro Civil e Identificación. Registros de Nacimiento, Matrimonio y Defunción años 1885-1920. Punta Arenas.

\section{Impresa}

MARTINIC B., MATEO 1971 José Nogueira, primer pionero y hombre de fortuna de la antigua colonia de Magallanes, a la luz de papeles inéditos. Anales del Instituto de la Patagonia, vol. 2. Punta Arenas, 1971.

1975 Origen y evolución de la inmigración extranjera en Magallanes entre 1870 y 1890. Anales del Instituto de la Patagonia, vol. 6. Punta Arenas, 1975.

URIBE URIBE, JOSE 1996 Album y biografía del Boxeo Regional 1920-1980. Punta Arenas.

8 Aunque no hemos encontrado la evidencia confirmatoria, es posible que esta actividad comprendiera asimismo el entrenamiento del personal que hacía la conscripción militar. 


\section{APÉNDICE}

Lista de portugueses arribados a Magallanes entre 1871 y 1890*

1.- $\quad$ Antonio Jacinto

2.- José Alvarez

3.- Joaquín de Almeida

4.- Juan Pedro

5.- $\quad$ Manuel Pereira

6.- José Alves Brazil (a)

7.- $\quad$ Germán Antonio Araujo

8.- José Branco

9.- Nicolás Araujo

10.- Antonio da Silva

11.- Juan José da Cruz

12.- José Teixeira

13.- $\quad$ Manuel da Pino

14.- José Lobo Oliveira

15.- $\quad$ Antonio da Cena

16.- Manuel Oliveira

17.- $\quad$ Antonio Nuñez

18.- José Lorenzo

19.- $\quad$ Manuel de Souza ¿Betancourt? (a)

20.- Antonio Broladón

21.- $\quad$ Francisco Gómez (b)

22.- Francisco Souza

23.- Joaquín Barres

24.- Benito C. González

25.- Juan J. Cruz

26.- Antonio J. da Freitas

27.- Antonio Bento
28.- Joaquín (se ignora el apellido)

29.- $\quad$ Antonio Soares o Suárez

30.- $\quad$ Antonio Piñeiro

31.- $\quad$ Antonio Araujo

32.- Manuel Antonio Mostacio

33.- $\quad$ Antonio Manuel Santos

34.- $\quad$ Filemón Andreadi

35.- Manuel Gómez Souza

36.- Juan Manuel da Cruz

37.- Manuel Suárez Silveira

38.- $\quad$ Alberto Madeiros

39.- José Ventura

40.- Juan Tomás

41.- $\quad$ Antonio Corado

42.- Juan Rodríguez Pérez

43.- $\quad$ Carlos Chapel

44.- $\quad$ Teodoro Antúnez

45.- $\quad$ Benito Cardozo (b)

46.- $\quad$ ¿? Salgueiro

47.- Joaquín Gómez

48.- Juan Vieira (a)

49.- $\quad$ Antonio Pereira

50.- Juan Silva

51.- $\quad$ Gonzalo Correa (b)

52.- $\quad$ Luis Miguel López

53.- José Luis Antonio

54.- $\quad$ Serafín Araujo (b)

(a) Individuo de raza blanca (comprobado)

(b) Individuo de raza negra (id.)

Nota: los números 7 (Germán Antonio Araujo) y 31 (Antonio Araujo), por una parte, y 24 (Benito C. González) y 45 (Benito Cardozo), por otra, podrían corresponder a dos mismas personas.

* Tomada de roles o contratos de embarque, Archivo José Nogueira, y otras fuentes. En muchos casos la ortografía es dudosa. 
